\title{
Possibilities of collecting, analysing and visualizing groundswell communication data in a global environment
}

\author{
Michal Kubovics ${ }^{1, *}$, Anna Zaušková ${ }^{1}$ \\ ${ }^{1}$ University of Ss. Cyril and Methodius in Trnava, Faculty of Mass Media Communication, Námestie \\ Jozefa Herdu 2, 91701 Trnava, Slovakia
}

\begin{abstract}
Research background: The groundswell is an undoubted threat, but also a potential of companies. It is important for business entities with a global scope to monitor potential customers and consumers when behaving in a digital environment, because there is a possibility of creating a so-called groundswell, which can have global adverse effects on the company's sales and reputation. Only if we continuously monitor and evaluate all aspects, including the activity of the groundswell, can we predict and intervene at the right time.

Purpose of the article: The aim of the paper is to map the possibilities of data collection, analysis, and visualization, which were created in the digital media environment using the groundswell. The partial goals are in the study of theoretical background and analysis of the possibilities of data collection, research, and evaluation.

Methods: We used the methods of thematic analysis for the theoretical framework of the paper. To explore the possibilities, we used the method of content analysis of individual tools and outputs of digital media, which provide data, analysis, and subsequent visualization. Qualitative analysis of the content of texts allows a basic prerequisite for fulfilling the objectives of the paper. Subsequent content analysis of tools and options enables comprehensive fulfilment of the main goal.

Findings \& Value added: The presented paper focuses on specific possibilities of data collection originating from the digital environment, which can be used for further research of the issue and the design of a future system that would avert the global devastating effects of the groundswell. This is because only the prediction of behaviour and immediate response allows for a better response to a crisis.
\end{abstract}

Keywords: data collection, data analysis, data visualization, communities, groundswell

JEL Classification: $D 8 ;$;3; M39

\footnotetext{
*Corresponding author: kubovics1@ucm.sk
} 


\section{Introduction}

According to Li and Bernoff, the groundswell is characterized as a set of people who share advice with each other and do not need corporations to do so. The authors also discuss the three pillars: people, technology, and economics. The first characterized pillar is people. People have moved from corporate and institutional power to communication within their communities. They were helped by social networks, blogs, discussion groups, Q\&A, and social communities and wiki users. Another pillar is technology, which is conditioned by technological development. During the development of digital devices, people began to connect with other people on a global scale. (Li \& Bernoff, 2011) Also, with the advent of smartphones, an environment has been created that is accessible to all people at any given time on a global scale. The last pillar is the economy, where the authors describe that in the Internet environment, 14.6 billion dollars was spent in 2007 through an Internet exchange of funds. In 2021, it's up to 4.28 trillion dollars. At the same time, the predictions have an increasing character and by 2024 the assumption is 6.38 trillion dollars. (Global Retail ECommerce Market Size 2014-2023, 2021)
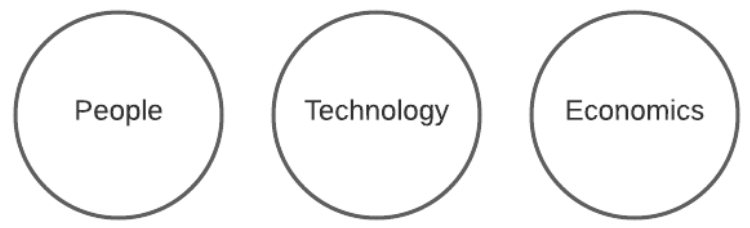

Figure 1. Connection of the three groundswell pillars.

Source: Own source (2021)

Another part is the so-called POST method, which is the basis for insight into the thinking of the groundswell. It consists of the following components: people, goals, strategy, technology. The following table provides an overview of the POST method with a description of key questions and an example of completion by Li and Bernoff.

Table 1. Groundswell POST method.

\begin{tabular}{|l|l|l|}
\hline $\begin{array}{l}\text { Groundswell } \\
\text { component }\end{array}$ & Key question & Description of the key question \\
\hline People & $\begin{array}{l}\text { What are } \\
\text { consumers ready } \\
\text { for? }\end{array}$ & $\begin{array}{l}\text { It is important to understand where people are talking } \\
\text { about a business entity or business segment, such as a } \\
\text { community on social networks, discussion forums, } \\
\text { Wikipedia, or a blog. }\end{array}$ \\
\hline Goals & $\begin{array}{l}\text { What goals are } \\
\text { needed for a } \\
\text { business entity? }\end{array}$ & $\begin{array}{l}\text { For example, businesses can get feedback from consumers } \\
\text { and potential consumers. We can develop brand } \\
\text { recognition, promote products, use the groundswell for } \\
\text { research purposes, or internally improve communication } \\
\text { with employees. }\end{array}$ \\
\hline Strategy & $\begin{array}{l}\text { What do business } \\
\text { consumers need to } \\
\text { do? }\end{array}$ & $\begin{array}{l}\text { In the context of this question, it may be an increase in } \\
\text { involvement in the business entity, product awareness, or } \\
\text { helping customers to understand the product or service. }\end{array}$ \\
\hline Technology & $\begin{array}{l}\text { What platform } \\
\text { should be used to } \\
\text { achieve the goals? }\end{array}$ & $\begin{array}{l}\text { In accordance with technologies, there are various } \\
\text { platforms such as Wikipedia, blogs, social networks, etc. }\end{array}$ \\
\hline
\end{tabular}

Source: Own source with https://www.stayonsearch.com/so-what-does-the-groundswell-mean (2021)

The groundswell undoubtedly belongs to the global sphere, this is also confirmed in the strategy of companies, as stated by the authors Kozlenková and collective. (Kozlenková et 
al., 2021) As stated by Bezáková and collective, it is important to think about the legal aspects of the digital environment and the groundswell. (Bezáková et al., 2021) According to the author Neu and collective, within social media and discussions, it is possible to collect a large amount of data that can be evaluated. (Neu et al., 2020) According to Gulliver, a groundswell is needed that leads to activation, specifically in an environment of ecological thinking and change. (Gulliver et al., 2020) Highly professional work in the field of data visualization was provided by the authors Stalph and Heravi, who described the ideal possibilities of data visualization in communication. (Stalph and Heravi, 2021) Zhang and collective have been involved in combining data visualization and a target group affected by certain aspects. (Zhang et al., 2019) On the other hand, as Nærland and Engebretsen emphasize in data visualization, a clear interpretation of the data is very important, which can be manipulated under certain conditions. The authors also emphasize the need for proper data collection, analysis, and interpretation. (Nærland and Engebretsen, 2021) Author Van Couvering defined a semiotic framework for analysing visual interactive elements on social networks. (Van Couvering, 2021) Author Cunha confirmed that even within the communication houses, employees are aware of the importance of the outputs and are more inclined to them. (Cunha, 2020) Rettberg defined new possibilities of data analysis in the field of social media. (Rettberg, 2020) Leading authors Yuand and Fang emphasize that the right visualization requires the right technology, as does groundswell data analysis. Technology interconnection is a necessary pillar. (Yuan and Fang, 2019) According to Andry, data visualization can also be understood as emotional visualization and can be better received. (Andry, 2020) From the point of view of introducing the process into visualization, it is important to mention the authors Verhulsdonck and Shahan, who in their paper form a model of the visualization process. (Verhulsdonck and Shah, 2021)

\section{Methods}

Within the methodology, qualitative and quantitative methods appear in the paper. A conditional part is a reliably defined research design with respect to the required topic. At the level of the qualitative component, it is research focusing on the data envelopment analysis of texts from highly professional sources, especially from scientific journals with high quality evaluation. The following are papers from conferences transformed into proceedings. Subsequently, professional texts in the form of literature and online processing are used. The aim of the paper is to summarize the results and display the current state of collection, analysis, and visualization of the groundswell, based on the analysis of previous knowledge from leading authors. The research questions formulated by the authors are:

- What data can be collected?

- How to properly analyse the data?

- How to visualize data correctly?

The paper uses quantitative methods of analysis of results from the scientific database Web of Science. Specifically, the keyword "groundswell" was searched. The result part of the paper contains specific numerical indicators for the number of papers in the given category, which can be very useful in further research, especially due to better categorization and the search for other relevant sources. The following criterion is the distribution of papers by years, where we examine in which period the most papers were written by professional authors. Using the analysis of abundance for the whole period, we can find out whether the topic is growing, stable or in stagnation. The keywords that are in the network diagram are also analysed. There are keywords with a frequency equal to or greater than three. The keywords that join the main keyword "groundswell" are so-called VOSviewer related keywords. In a similar way, the thematic areas related to the given keyword are analysed. The final part of the paper defines the most used tools for data collection, analysis and 
visualization originating from groundswell activities. We used the 10 most used tools according to Agarwal Manvi from Social Pilot, precisely because of the complexity of the results, which he defined as a leading author. (Agarwal, 2021)

\section{Results}

Within the results, we discuss the co-operation of factors resulting from the wide range of available scientific articles and literature. The results section leads to answers defined as scientific questions. As part of the analysis, we also focused on the current number and continuity of keywords that accompany the groundswell.

\section{The analysis of the keyword "groundswell"}

The analysis of the keyword "groundswell" yielded interesting findings. The research to date has focused mainly on the narrow profile of this issue. A minimum of authors deals with a broader context and clarification. The complete report contains 307 results after entering the keyword "groundswell". The following tree map shows the keyword in the categories in which it occurred.

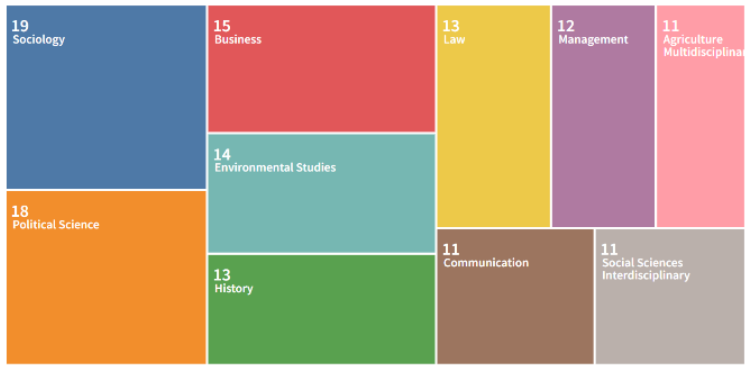

Figure 2. Web of Science - tree map of categories.

Source: Own source, Wos (2021)

As can be seen from the tree map, the largest representation of papers with the keyword "groundswell" is in the category "sociology" with the number of 19 , followed by the category "political science" with the number of 18 , "business" came in third, in fourth place with the number of 14 were "environmental studies" and in last place is the category of "history". The following diagram analyses the associated keywords and their links.

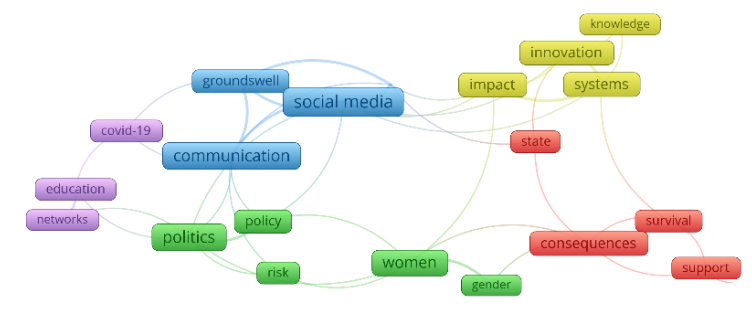

B vosviewer

Figure 3. Web of Science - diagram of keywords.

Source: Own source, VOSviewer (2021) 
It is clear from the above diagram that the keyword "groundswell" most often occurs in conjunction with the keywords "social media" and "communication" in a single cluster. Subsequently, there is another cluster with the dominant keyword "innovation" and "systems". Following is the cluster with the most frequent keyword "consequences", followed by the cluster with the keywords "women" and "politics". Expressions are closed by the last cluster where "education" dominates. The following overview in the form of a tree map provides an overview of the years in which papers to the keyword "groundswell" were published.

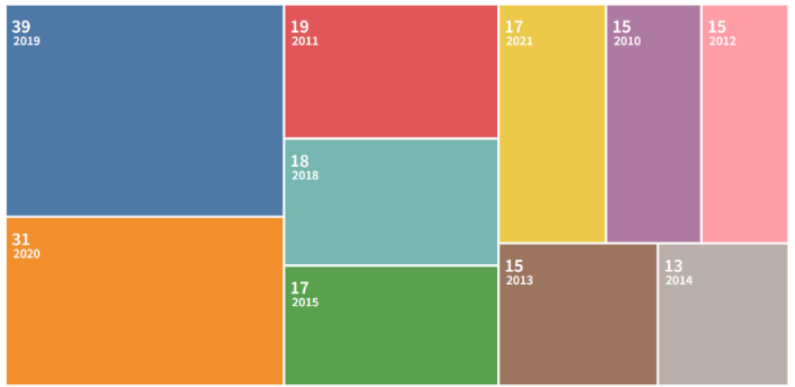

Figure 4. Web of Science - tree map of years.

Source: Own source, WoS (2021)

Within the evaluation we can observe that 39 results are from the year 2019. The next occurrence is from the year 2020. The year 2011 placed third, with the number of 19. In fourth place is the year 2018 with the number of 18 and in fifth place with the number of 17 is the year 2015. The results suggest that the issue is more active among experts in recent years

The analysis of the keyword "groundswell" in conjunction with the keyword "data collection, analysis, and visualization"

When analysing the keyword "groundswell", there are specific papers to the groundswell, but in connection with the measurement, or with the collection, analysis, and visualization of data. There are papers in the search that are not directly related to the groundswell and that are from a different segment.

\section{Why do data collection, analysis, and visualization?}

The analysis of available resources resulted in the form of a systematic elaboration of the theme of the groundswell. On the other hand, there is a continuity of data collection, analysis, and visualization. This tripartite is important mainly due to the need for businesses to constantly measure and evaluate groundswell activities.

\section{What tools can we use to collect, analyse, and visualize data?}

The given sources led to the conclusion in the form of a division of tools. After studying the possibilities, two categories open and these are custom tools that are designed for a specific purpose and are developed by specialized development companies or internal departments. On the other hand, there are tools that are open to the public and can be free or for an adequate regular contribution. 


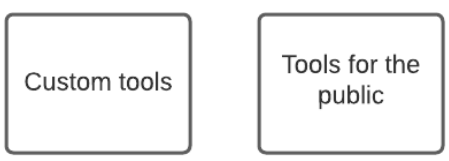

Figure 5. Tools

Source: Own source (2021)

The analysed sources also revealed the fact that the choice of category depends on the financial resources that business entities spend on data collection, analysis, and visualization. Especially because custom tools are to a greater extent financially remunerated by a higher amount than tools for the public. If a business entity does not need its own system for its goals, which can be very specific, it can reach for a public tool and thus streamline the work with data based in the groundswell.

\section{What data to collect?}

By analysing the available sources, we have concluded that the groundswell activity generates many data packets that are interconnected. As can be seen from these sources, the data is stored, either on social media directly in the internal advertising and insight system or on the other hand on websites, where a measurement tool must already be deployed directly on the site so that businesses can collect data. It is also important to mention the legal framework for data collection, where it is clear from the sources that there are certain restrictions in this respect. Subsequently data collectivization focuses on data coming from blogs, discussion forums or Wikipedia. For other systems that are not directly on popular social media, it is important to deploy the right measurement tool. The data can be, for example, from engagement, views, sentiment, number of reactions, etc.

\section{How to analyse data correctly?}

Broad-spectrum data are used for data analysis. According to the sources, the analysis is carried out within the framework of internal and external tools within the social media. The interpretation or understanding of the data is up to the recipients themselves. The analysis provides a description of the recorded data. Recommendations are usually made by specific experts focusing on the groundswell. We can analyse many variables. In the conclusion, it is possible to find the right content for the target group of the groundswell and thus prevent possible collisions and collisions with the groundswell. It is important to think about the groundswell behaviour and prediction in the analysis. According to the sources, this step is in the competence of social media experts.

\section{How to visualize data correctly?}

Data visualization is an absolutely important element in data perception. Expert sources have brought the result that visualization in the groundswell is implemented both in the internal management of social media and in external tools for the management of social media. The need to choose the right visualization elements is confirmed. It is also important to pay attention to the target groups of recipients and the transmission of data must be in accordance with their needs and possibilities.

\subsection{Tools for data collection, analysis, and visualization}

The following section shows examples of tools that can be used to collect, analyse, and visualize data. The following table lists the most used tools by leading author Agarwal Manvi. 
Table 2. Manvi Agarwal Tools.

\begin{tabular}{|l|l|}
\hline 1. & SocialPilot \\
\hline 2. & Agropulse \\
\hline 3. & Google Analytics \\
\hline
\end{tabular}

Source: https://www.socialpilot.co/social-media-analytics-tools (2021)

SocialPilot is a tool that has proven to be one of the most direct analytical tools. It is very suitable for monitoring the groundswell. Business entities are allowed to monitor a wide range of metrics, which can also be visualized. Within the tool it is possible to follow TikTok, Facebook, Twitter, LinkedIn, Instagram, Google My Business, Pinterest and VK. The data comes from variables such as engagement, audience size, audience demographics, etc.

Agropulse primarily analyse the performance of individual content or monitor keywords and hashtags. This tool has sophisticated analytical and reporting functions and is therefore very suitable for data analysis and visualization. It also provides analysis of groundswell competition and community reporting, which is a decisive factor in attempts to change the behaviour of the groundswell.

Google Analytics, a tool used primarily to manage websites, but it is also one of the best tools to track live activity within the groundswell. It helps businesses to analyse potential consumers in the form of visitors, where it is possible to measure the best content in the form of a campaign setting. The advantage is that the tool is completely free and allows companies to set precise goals for businesses.

\section{Discussion}

The analysis provided findings on the possibilities of the groundswell and especially on what can be collected. Specifically what variables. How it is possible to subsequently analyse the given variables and ultimately visualize them. During the research, we came across a clause about a possible devastating effect for companies that can be created by the groundswell. It means the constant neglect of the community, which can within the discussion cause a drop in profits. Businesses should consider the fact within the history of the groundswell, as reported by the sources examined, that the groundswell has affected small, medium, and large enterprises. Only further research will provide important insights into what is happening in the groundswell regions and whether businesses are monitoring or even acting on the groundswell in some way. The analysis also revealed the insufficient examination of groundswell. Especially from a marketing point of view, this finding is crucial, because if we do not affect the groundswell in a sufficient time interval, it can get out of control for businesses. Therefore, it is important to collect and evaluate data within the groundswell. Because, as the leading authors have pointed out, only a quick response that is in a relatively short period of time can help us. All claims about data collection are amplified by the fact that for business entities, the subsequent visualization of data is crucial for easy and clear readability. Business entities will thus get an excellent tool for groundswell analysis. In the same way we can evaluate the POST method. The functionality of this method is valid from its inception to the period of analysis in the presented paper, but it is necessary to work on improvements to this method as well as to clarify the target group and especially communities. As part of the analysis of available sources, relevant findings from the area of data collection, analysis and visualization also emerged. There is a wide range of tools that allow all the activities of this tripartite. 


\section{Conclusion}

The aim of the paper was fulfilled, we clarified all three research questions we formulated. With the help of the paper, we obtained an up-to-date overview of the current state of the issue. The analysis concluded that the groundswell is examined at a low level, and it is very important to develop the topic in further scientific questions and research. In the analysis, the authors detected that in recent years the topic of the groundswell has been addressed more, but the groundswell has a slightly declining trend. Through a summary of the analysis of associated keywords, we can say that the groundswell currently includes keywords such as "innovation", "politics", "consequences", "education", etc., and on a large scale, "social media". The review also provides a look at the topic as a category of sociology. In the conclusions, we defined all important aspects. The limits of the study may be in the availability of the resources used. It is important to continue researching and clarifying the widest possible field of the groundswell.

\section{Acknowledgements}

The research was supported by the Scientific Grant Agency of the Ministry of Education, Science, Research and Sport of the Slovak Republic and the Slovak Academy of Sciences (VEGA, No. 1/0458/21) under the project entitled "Management of the "groundswell" concept by business entities in promotion of environmentally-friendly products in times of technology interference".

\section{References}

1. Agarwal, M. (2021). Top 14 free and paid social media analytics \& reporting tools for 2021. SocialPilot. https://www.socialpilot.co/social-media-analytics-tools

2. Andry, T. (2020). Visualisation de données et design émotionnel peuvent-ils se conjuguer? Communiquer. Revue de communication sociale et publique, 28, 53-71.

3. Bezáková, Z., Madleňák, A., \& Švec, M. (2021). Security Risks of Sharing Content Based On Minors By Their Family Members On Social Media In Times Of Technology Interference. Media Literacy and Academic Research, 4(1), 53-69.

4. Cunha, R. (2020). Journalism, data visualization, and perception about readers. Brazilian Journalism Research, 16(3), 526-549.

5. Gillin, P. (2021). Groundswell is an intelligent approach to social media marketing. Social Media Today. https://www.socialmediatoday.com/content/groundswellintelligent-approach-social-media-marketing

6. Global retail e-commerce market size 2014-2023. (2021). Statista. https:/www.statista.com/statistics/379046/worldwide-retail-e-commerce-sales/

7. Gulliver, R., Fielding, K. S., \& Louis, W. (2020). The characteristics, activities and goals of environmental organizations engaged in advocacy within the australian environmental movement. Environmental Communication, 14(5), 614-627.

8. Kozlenkova, I. V., Lee, J.-Y., Xiang, D., \& Palmatier, R. W. (2021). Sharing economy: International marketing strategies. Journal of International Business Studies, 52(8), 1445-1473.

9. Li, C., \& Bernoff, J. (2011). Groundswell: Winning in a world transformed by social technologies (Expanded and rev. ed). Harvard Business Review Press. 
10. Nærland, T. U., \& Engebretsen, M. (2021). Towards a critical understanding of data visualisation in democracy: A deliberative systems approach. Information, Communication \& Society, 1-19.

11. Neu, D., Saxton, G., Everett, J., \& Shiraz, A. R. (2020). Speaking truth to power: Twitter reactions to the panama papers. Journal of Business Ethics, 162(2), 473-485.

12. Rettberg, J. W. (2020). Situated data analysis: A new method for analysing encoded power relationships in social media platforms and apps. Humanities and Social Sciences Communications, 7(1), 5.

13. Stalph, F., \& Heravi, B. (2021). Exploring data visualisations: An analytical framework based on dimensional components of data artefacts in journalism. Digital Journalism, 123.

14. Van Couvering, E. (2021). Faces and charts: Platform strategies for visualising the audience, the case of Facebook. Information, Communication \& Society, 1-18.

15. Verhulsdonck, G., \& Shah, V. (2021). Lean data visualization: Considering actionable metrics for technical communication. Journal of Business and Technical Communication, 35(1), 57-64.

16. Yuan, S., \& Fang, W. (2019). Application of data visualization technology in the process of teaching. 2019 International Conference on Arts, Management, Education and Innovation (ICAMEI 2019). 2019 International Conference on Arts, Management, Education and Innovation.

17. Zhang, J., Cui, X., Liu, H., Han, H., Cao, R., Sebrie, E. M., \& Yin, X. (2019). Public mobilisation in implementation of smoke-free Beijing: A social media complaint platform. Tobacco Control, 28(6), 705-711. 